\title{
WADAH AKTIVITAS SENI DIGITAL DAN KERAJINAN
}

\author{
Wandy $^{1)}$, Dewi Ratnaningrum ${ }^{2)}$ \\ 1) Program Studi S1 Arsitektur, Fakultas Teknik, Universitas Tarumanagara, wandytjia@yahoo.com \\ 2) Program Studi S1 Arsitektur, Fakultas Teknik, Universitas Tarumanagara, dewir@ft.untar.ac.id
}

\begin{abstract}
Abstrak
Perkembangan ilmu pengetahuan dan teknologi informasi menyebabkan perubahan besar di era ini. Salah satunya adalah pada aktivitas manusia sehari-hari. Jumlah komunitas mikro yang berdasarkan keahlian dan kemampuan telah muncul dan terbentuk dengan sendirinya serta mulai diserukan oleh para generasi muda. Hingga saat ini pengetahuan dan minat masyarakat tentang industri kreatif masih belum dapat terwadahi dan kebutuhan budaya yang terjadi telah berubah. Hal lain yang terjadi adalah kesenjangan antara bentuk pekerjaan yang dilakukan oleh para generasi muda adalah berbasis minat dan hobi yang disenangi sehingga membuat tingkat produktivitas juga meningkat. Salah satu sektor yang masih minim dan memiliki tingkat komunitas tinggi adalah kerajinan. Kerajinan merupakan salah satu dari sektor yang memiliki peran besar dalam ekonomi kreatif dan guna untuk pelestarian nilai-nilai budaya lokal. Oleh karena itu, dalam membantu perkembangan dan pertumbuhan ekonomi kreatif dan menjawab tantangan tersebut maka salah satu alternatif adalah dengan membuat proyek Digital Art and Craft Makerspace. Dengan menggunakan metode survei lapangan, dan tipologi maka diharapkan proyek dapat menjadi wadah bagi masyarakat khususnya kaum generasi muda dan penduduk lokal. Hubungan antara wadah kegiatan dan sumber daya manusia memiliki peranan penting. Tujuan Digital Art and Craft Makerspace dibangun adalah untuk menarik para generasi muda untuk dapat menyalurkan minat dan bakat mereka dengan bentuk pelatihan dan kebutuhan informasi yang memadai agar dapat berkreasi dalam menuangkan ide atau gagasan yang hasil akhirnya memiliki nilai budaya.
\end{abstract}

Kata kunci: generasi muda; ilmu pengetahuan; kerajinan; teknologi

\begin{abstract}
The development of science and information technology caused major changes in this era. One of them is in everyday human activities. The number of micro communities based on expertise and ability has emerged and formed by itself and started to be called upon by the younger generation. Until now the knowledge and interest of the community about the creative industry still cannot be accommodated and the cultural needs that have occurred have changed. Another thing that happens is that the gap between the forms of work carried out by the younger generation is based on interests and hobbies that are loved so that the level of productivity also increases. One sector that is still minimal and has a high community level is craft. Crafts are one of the sectors that have a large role in the creative economy and are used to preserve local cultural values. Therefore, in helping the development and creative economic growth and answering these challenges, one alternative is to create a Digital Art and Craft Makerspace project. By using the field survey method and typology, it is expected that the project can become a forum for the community, especially the younger generation and local residents. The relationship between container activities and human resources has an important role. The purpose of Digital Art and Craft Space is to attract young people to be able to channel their interests and talents with the form of training and adequate information needs so that they can be creative in expressing ideas or ideas whose end results have cultural values.
\end{abstract}

Keywords: craft; science; technology; young generation 


\section{PENDAHULUAN}

Millenial merupakan generasi yang lahir diantara tahun 1980 sampai 2000. Generasi ini adalah orang-orang dengan usia produktif yang merupakan penggerak ekonomi kreatif Indonesia. Generasi ini hidup bersamaan dengan perkembangan era digital dan internet. Mereka merupakan generasi yang terkena dampak yang sangat besar terhadap perkembangan teknologi. Salah satu perkembangan teknologi yang memberikan dampak yang sangat besar adalah internet. Dengan adanya perkembangan internet pada tahun 2000 hingga sekarang menjadikan anak-anak muda abad ini bertumbuh dengan mengalami transformasi gaya hidup yang drastis. Melalui internet pula, berbagai aktivitas dalam kehidupan mereka menjadi lebih mudah. Internet tidak hanya mengubah gaya hidup seseorang, tetapi mengubah pula generasi serta peradaban suatu bangsa. Melalui teknologi digital, generasi millennial tumbuh kreatif, berinovasi, dan membangun perekonomian Indonesia.

Di Jakarta sendiri terdapat banyak komunitas-komunitas yang memiliki keahlian dalam menghasilkan industri kreatif. Namun hingga kini pengetahuan dan minat masyarakat tentang industri kreatif masih belum dapat terfasilitasi dengan baik. Masyarakat masih memandang produk lokal dari industri kreatif dengan sebelah mata saja. Namun bagi kaum millenial sendiri ini adalah salah satu peluang dalam berbisnis dan menyalurkan minat terhadap era industri kreatif yang sedang berkembang.

Itulah sebabnya Digital Art and Craft Makerspace ini diajukan sebagai usulan proyek Studio Perancangan Arsitektur 8.27. Sebuah wadah yang didesain dengan maksud agar masyarakat dapat terfasilitasi dalam mengembangkan industri kreatif dengan keterkaitan teknologi secara mudah, menarik dan berkesan melalui metode yang inovatif dan kreatif. Dengan menggabungkan unsur pendidikan dan dalam beragam media diharapkan proyek ini dapat menyediakan saran pendidikan pelatihan yang bermanfaat bagi perkembangan industri kreatif nasional serta bersifat positif bagi perkembangan masyarakat di masa mendatang sekaligus merubah persepsi masyarakat mengenai hak kekayaan Indonesia.

\section{KAJIAN LITERATUR}

\section{Arsitektur Perilaku dan Kesejaman}

Arsitektur perilaku adalah arsitektur yang penerapannya selalu menyertakan pertimbanganpertimbangan perilaku dalam perancangan. Arsitektur muncul sekitar tahun 1950. Pertimbangan-pertimbangan ini pada awalnya dibutuhkan untuk perancangan obyek-obyek arsitektur tertentu, misalnya rumah sakit jiwa rehabilitasi narkoba, penjara, dan rumah sakit anak atau pusat autisme. Menurut Y.B Mangun Wijaya dalam buku Wastu Citra, arsitektur berwawasan perilaku adalah arsitektur yang manusiawi, yang mampu memahami dan mewadahi perilaku-perilaku manusia yang di tangkap dari berbagai macam perilaku baik itu perilaku pencipta, pemakai, pengamat juga perilaku alam sekitarnya. Disebutkan bahwa arsitektur adalah sebuah penciptaan suasana, yang artinya adalah perkawinan antara guna dan citra. Guna merujuk pada manfaat yang ditimbulkan dari hasil rancangan.

\section{Ekonomi Kreatif dan Industri Kreatif}

Istilah Ekonomi kreatif mulai dikenal secara global sejak munculnya buku "The Creative Economy : How People Make Money from Ideas" (2001) oleh John Howkins. Howkins dengan ringkas mencoba mendefinisikan Ekonomi Kreatif, yaitu "The creation of value as a result of idea". Kegiatan ekonomi kreatif mengharuskan pelakunya untuk memanfaatkan waktu dan menghasilkan ide demi kemajuan. Di Indonesia, salah satu strategi dalam pembangunan ekonomi dan industri yakni dengan pengembangan industri kreatif.

Industri kreatif adalah bagian tak terpisahkan dari ekonomi kreatif. Republik Indonesia menyadari bahwa ekonomi kreatif, yang berfokus pada penciptaan barang dan jasa dengan mengandalkan keahlian, bakat, dan kreativitas sebagai kekayaan intelektual adalah harapan bagi ekonomi Indonesia untuk bangkit bersaing dan meraih keunggulan dalam ekonomi global. 


\section{Makerspace}

Makerspace adalah lingkungan fisik yang mempromosikan dan mewadahi komunitas, pembelajaran, dan pembuatan. Bentuk fisik sebuah ruang terdapat berbagai macam seperti $h u b$, laboratorium, perpustakaan, ruang pembuatan produk, dan ruang kerja bersama. Namun ruang tersebut juga memberikan peluang untuk terlibat dengan orang-orang, ide, dan teknologi, kemudian mengalami budaya partisipatif dan mendapatkan literasi dan keterampilan yang dibutuhkan untuk menjadi makmur di abad ke-21.

\section{Digital Art}

Digital Art (Seni Digital) dapat diartikan sebagai metode/ teknik pengekspresian pikiran dan perasaan dalam bentuk visual/ elektronik. Biasanya dengan bantuan sebuah software/ perangkat. Bisa dengan program khusus komputer maupun aplikasi ponsel. Berbagai istilah telah digunakan untuk menggambarkan proses ini, diantaranya seni komputer (computer art) dan seni multimedia (Multimedia Art). Bahkan ada juga yang menyebutnya sebagai "teknik manipulasi gambar/ foto-foto di mana para pengguna bisa meng-scan gambar atau langsung di foto dengan kamera untuk kemudian di edit.

\section{METODE}

Dalam penyusunan laporan perancangan ini, beberapa tahapan dasar yang telah di lalui dalam suatu perancangan proyek, dirangkum secara sistematis sehingga dapat menambah pengetahuan megenai proyek ini. Keseluruhan tahapan yang menjadi data yang disusun menjadi satu kesatuan rangkaian penulisan dengan pembahasan yang dimulai secara deduksi dari yang sifatnya umum ke khusus sesuai dengan proyek yang direncanakan. Dalam hal ini, tahapan yang termasuk dalam ruang lingkup bahasan laporan antara lain:

a. Studi terhadap hubungan arsitektur, tipe dan perilaku serta nilai kesejamanan dalam hal ini keterkaitan dengan generasi millenial.

b. Studi terhadap karakteristik generasi millenial dengan menerapkan interdisplin.

c. Studi terhadap perkembangan millenial terhadap industri kreatif

d. Studi tipologi dari proyek-proyek serupa.

e. Survei awal dan pendataan awal keadaan lingkungan sekitar tapak.

f. Analisis tapak dan lingkungan.

g. Pengolahan data dan studi pustaka sehingga didapatkan karakteristik proyek yang berguna untuk perancangan awal.

h. Pemprograman aktivitas dan fasilitas, sehingga semua aktivitas dapat berjalan secara sinergis dan bekelanjutan.

\section{DISKUSI DAN HASIL}

\section{Analisa Kawasan}

Analisa kawasan dimulai dari DKI Jakarta, dengan menganalisa titik-titik budaya di satu Jakarta agar mendapatkan kawasan yang tepat dalam menerapkan program konsep seni kriya. Presentase titik-titik budaya di dominasi di daerah Jakarta Selatan. Kawasan yang dipilih dari satu Jakarta adalah Jakarta Selatan yang merupakan populasi terpadat ketiga di antara lima kota di Jakarta, setelah Jakarta Timur dan Jakarta Barat. Pusat administrasi berada di Kebayoran Baru. Melihat presentase titik budaya yang ada, untuk mendukung kawasan ini dibutuhkan akses yang tinggi agar dapat dicapai oleh para pelaku kegiatan dari proyek ini, mulai dari para generasi mudam seniman, dan wisatawan. Jakarta Selatan menjadi salah satu kota madya yang memiliki titik bentuk-bentuk budaya yang tersebar di Jakarta Selatan dan termasuk salah satu kota madya yang memiliki jumlah millenial terbanyak dan beraktivitas tidak hanya pagi hari tapi malam hari di berbagai titik-titik budaya tersebut. 


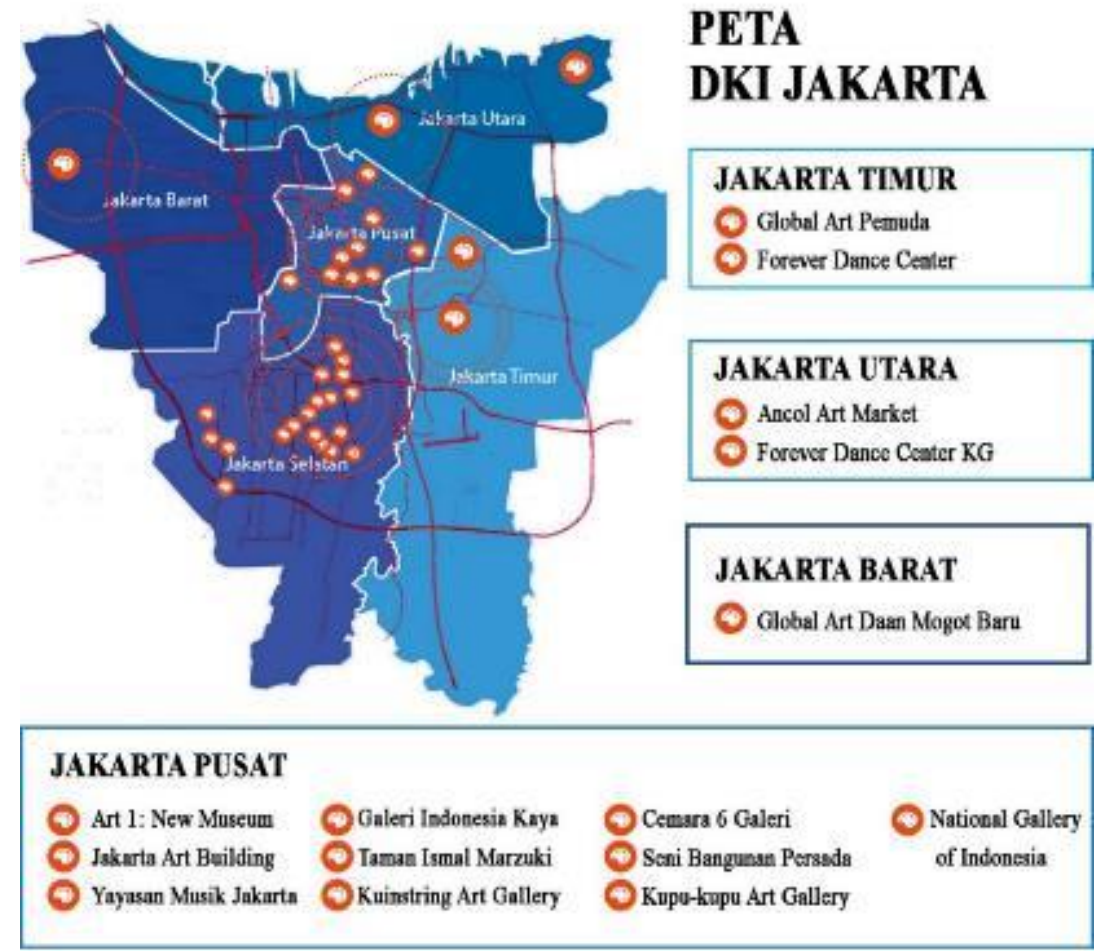

\begin{tabular}{|c|c|c|}
\hline \multicolumn{3}{|c|}{ JAKARTA SELATAN } \\
\hline $\begin{array}{l}\text { Komuanitus Saliharn } \\
\text { Dialogue } \\
\text { Edwis's Gallery } \\
\text { The Papilion } \\
\text { Ruci Art Space } \\
\text { Philo Art Space }\end{array}$ & $\begin{array}{l}\text { Galeri Pot } \\
\text { Galeri Hadiprana } \\
\text { Senggar Tari Tradisional Yudha Asri } \\
\text { Gallery Kemang } 58 \\
\text { 2Madison Gallery } \\
\text { Co Art Space }\end{array}$ & $\begin{array}{l}\text { Biasa Art Space Jakarts } \\
\text { KOI Kemang } \\
\text { Bartcle's Gallery } \\
\text { Suar Art Space } \\
\text { The Leouardi Studio \& Art Space } \\
\text { Garis Art Space }\end{array}$ \\
\hline
\end{tabular}

Gambar 1. Titik-titik Bentuk Budaya Sumber : Penulis, 2019

Dari analisa yang dilakukan dipilih bahwa daerah Kemang, kelurahan Bangka dipilih menjadi daerah yang akan diambil untuk menentukan lokasi tapak dari proyek sehingga dilakukan pertimbangan-pertimbangan untuk mendapatkan kesimpulan bahwa daerah Kemang cocok untuk proyek yang akan dibangun.

\section{GENERAL FUNCTION CIT Y}

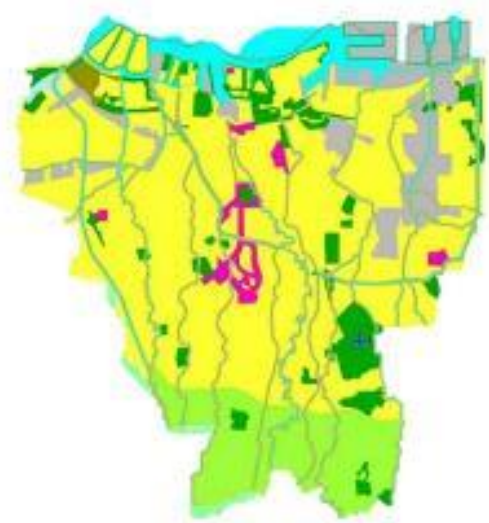

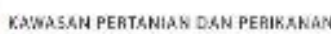
KAWASGM INDUSTR:

KAWASRR TERQUKG HIJRU KOK LIMDURE

KAWASART TERBUKA NOH HIJAU

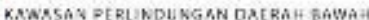

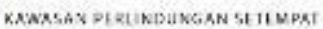

KNAKSAY SUAKA ALAN

K.NWNSAY PERMUKIMAS

KEWLSAN PUSAT PEROAGGHGAN DAN JASA

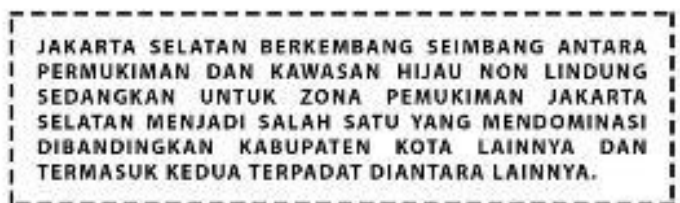

Gambar 2. General Function City

Sumber: Penulis, 2019 


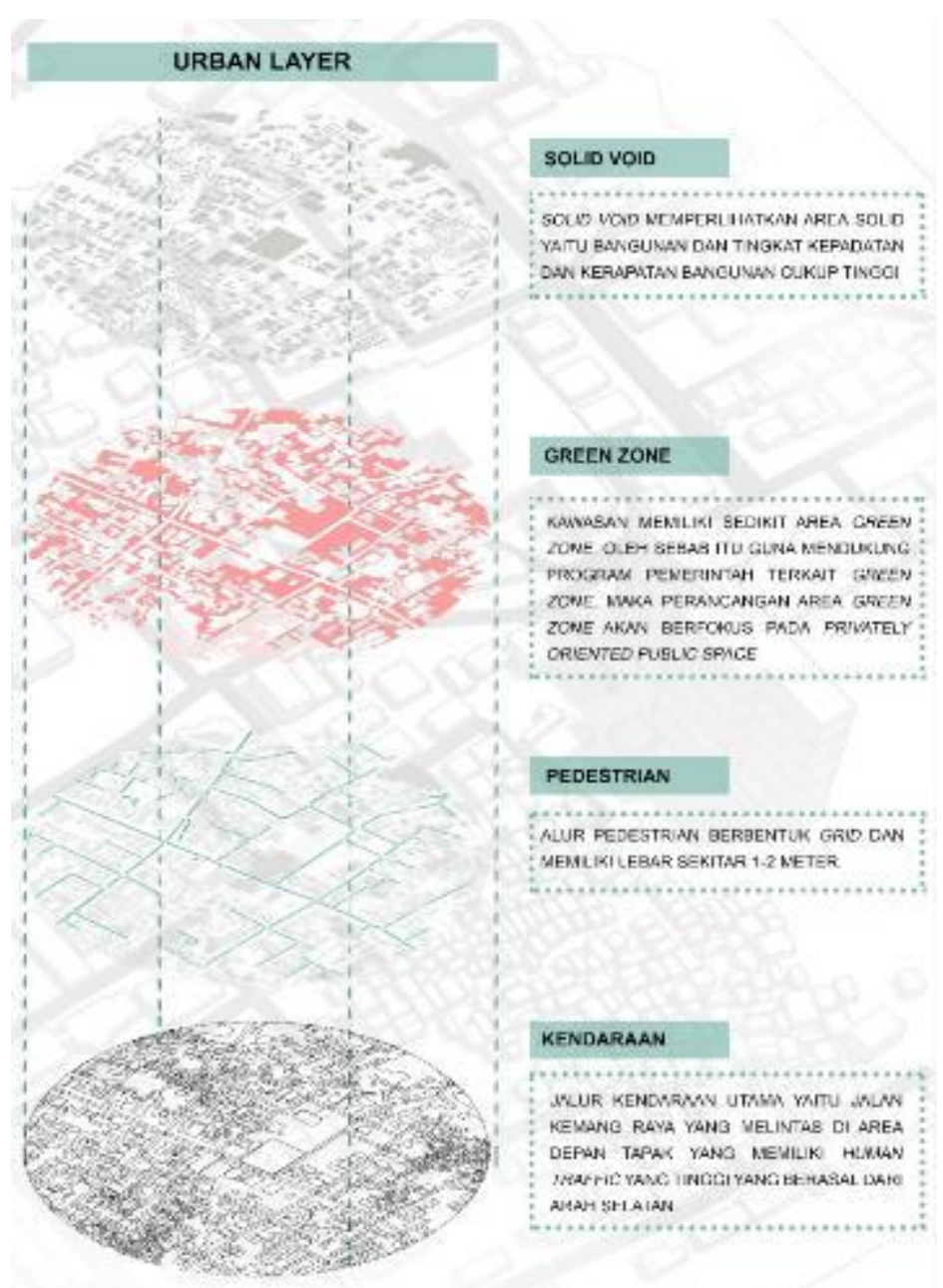

Gambar 3. Analisa Kawasan Kemang

Sumber: Penulis, 2019

\section{Analisa Tapak}
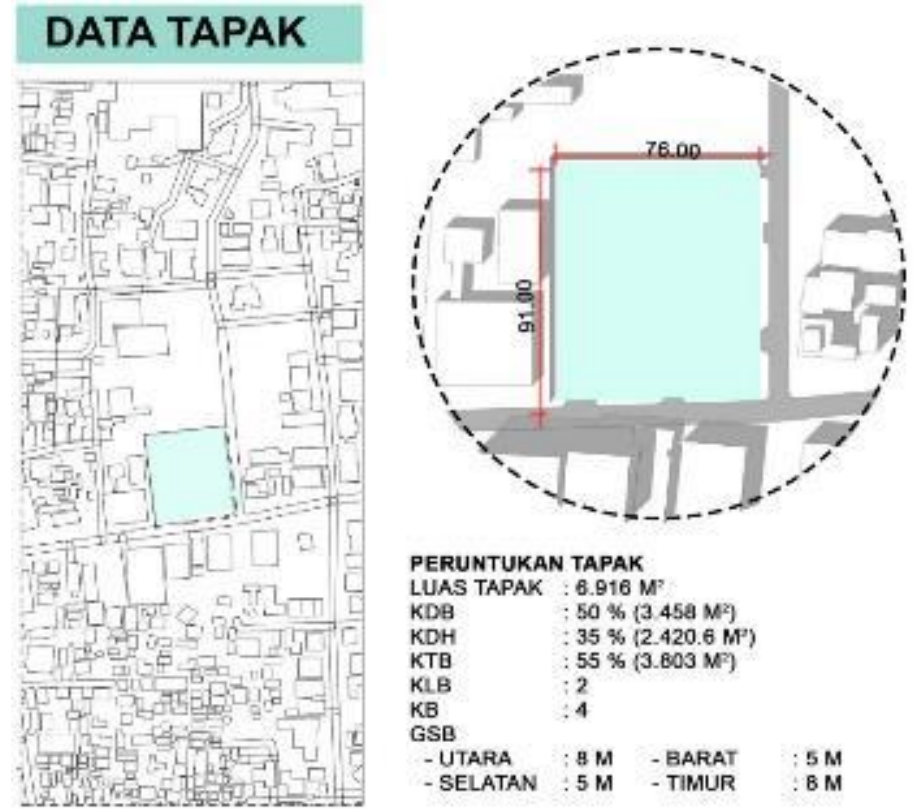

Gambar 4. Data Tapak

Sumber: Penulis, 2019 
Dari hasil analisa yang dilakukan, dapat dikatakan bahwa kawasan ini cocok dengan proyek yang akan dibuat dilihat dari hasil analisa, sehingga terpilihnya kemang sebagai kawasan terpilih. Setelah tapak terpilih, maka dilakukan analisa dan peninjauan lebih lanjut. Analisa dilakukan berdasarkan beberapa aspek. Berikut dijabarkan analisa terhadap tapak.

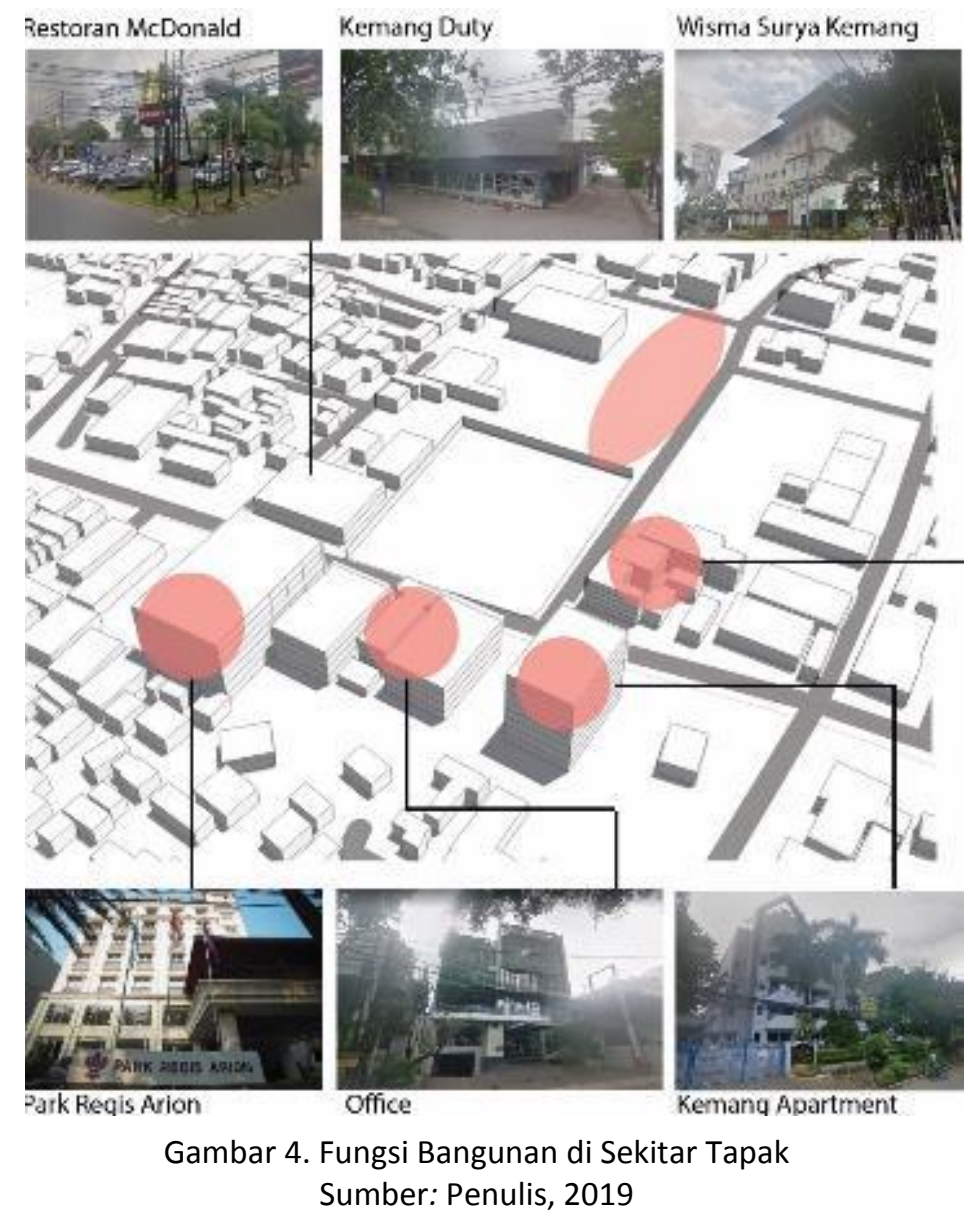

Pada gambar tersebut, dapat dilihat fungsi eksisting di kawasan sekitar tapak memiliki fungsi seperti cafe, apartmen, galeri, dan hotel, dimana fungsi eksisting ini cukup mendukung pada tapak. Digital Art and Craft Makerspace berkaitan erat dengan parawisata dan memiliki nilai jumlah yang mahal dan kawasan Kemang merupakan kawasan yang cukup di dominasi oleh kaum generasi muda dan turis.
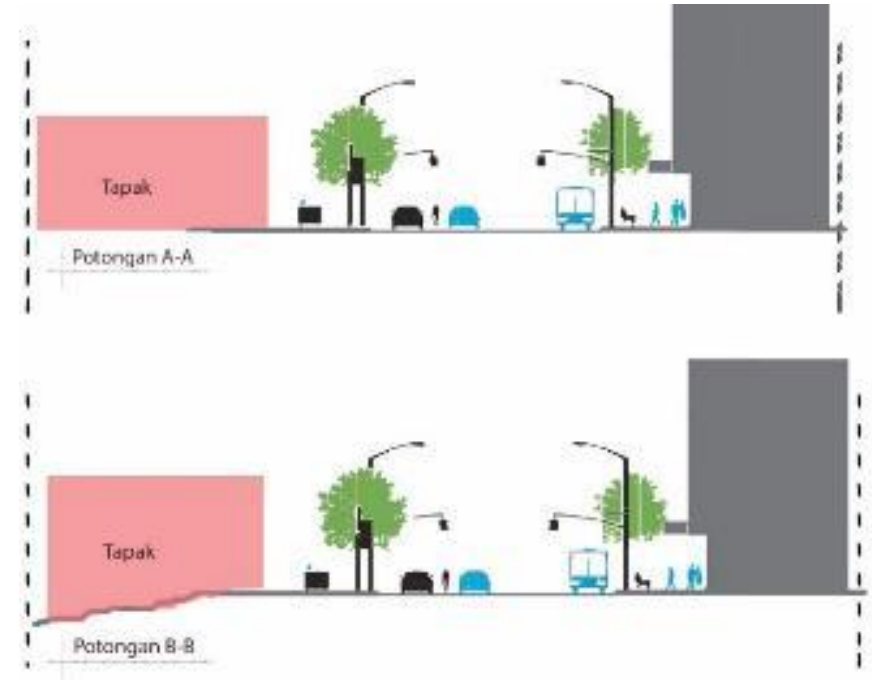

Gambar 5. Analisa View

Sumber: Penulis, 2019 
Pada analisa terkait view, arah yang paling baik adalah menghadap arah timur yang di lewati oleh jalan utama yaitu Jalan Kemang Raya, yang dapat digunakan sebagai potensi arah pengunjung datang. Untuk sirkulasi karena posisi tapak di bagian ujung jalan dan memiliki 2 sisi yang dekat jalan raya maka untuk aksesbilitas akan berfokus pada area sisi utara dan timur.

\section{Konsep}

Konsep perancangan pada proyek ini berfokus pada tema utama yaitu wadah pengembangan dengan mengambil konsep "Self-handmade" yang berarti seseorang telah melalui proses pelatihan dalam bentuk pengajaran yang dilandasi oleh keinginan dan hobi dari para sasaran. Self-hadmade ini juga merupakan perwujudan dari budaya dimana diharapkan seorang selfhandmade menjadi lebih dapat mengolah kemampuan pribadi yang berkontribusi di bidang ekonomi kreatif. Desain bangunan ini dapat membuat pelaku atau pengguna merasa dapat mengeksplor diri mereka sehingga mereka akan merasa nyaman dan mudah dalam berkreasi untuk menuangkan ide-ide kebaharuan dalam hal ini di bidang Digital Art dan Kerajinan. Bangunan dapat memiliki bentuk ruang yang berbeda dan unik karena konsep ini akan membuat seseorang menginterpretasikan ide-idenya menjadi hal yang unik dan berbeda dari yang lain dan dapat membantu mengembangkan ide-ide dasar secara berkelompok maupun individu.

\section{Zonasi Tapak}

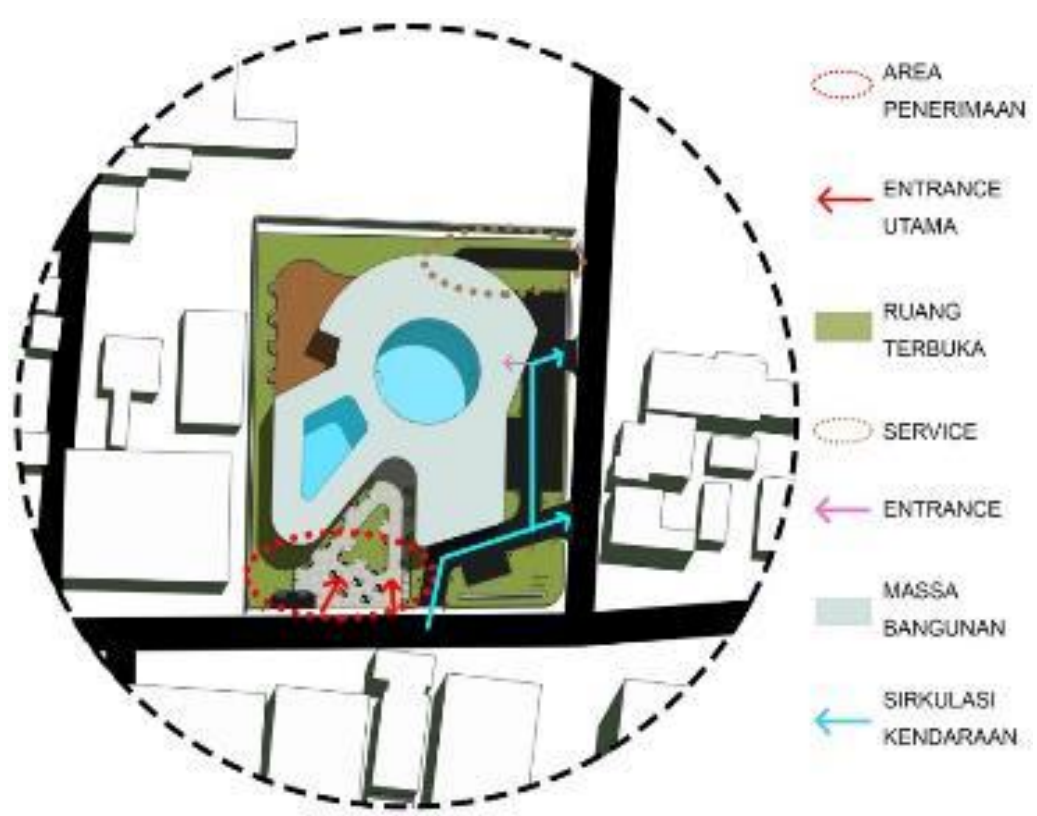

\footnotetext{
$\ldots$ RUANG TERBUKA YANG BERADA DI BAGIAN DEPAN MERUPAKAN FOKUS UTAMA

.... karena merupakan muka utama bangunan dan berhadapan dengan ENTRANCE UTAMA

$\longleftarrow$ ENTRANCE UTAMA LANGSUNG BERHADAPAN TERLEBIH DAHULU DENGAN RUANG TERBUKA DAN VEGETASI YANG BERADA DI DEPAN TAPAK

ENTRANCE LAIN YANG DAPAT DIAKSES DARI AREA PARKIR

:.... AREA UTILITAS DAN SERVICE DILETAKKAN DI BELAKANG, SEHINGGA PROSES LOADING DOCK DILAKUKAN DI BAGIAN BELAKANG TAPAK
}

MASSA BANGUNAN MEMIUIKI 2 VOID DAN MEMANJANG DENGAN TUJUAN UNTUK MENGHINDARI BENTUK MASSA YANG PADAT DAN CAHAYA MATAHARI BISA MASUK 
Tabel 1. Proses Gubahan Massa Sumber: Penulis, 2019
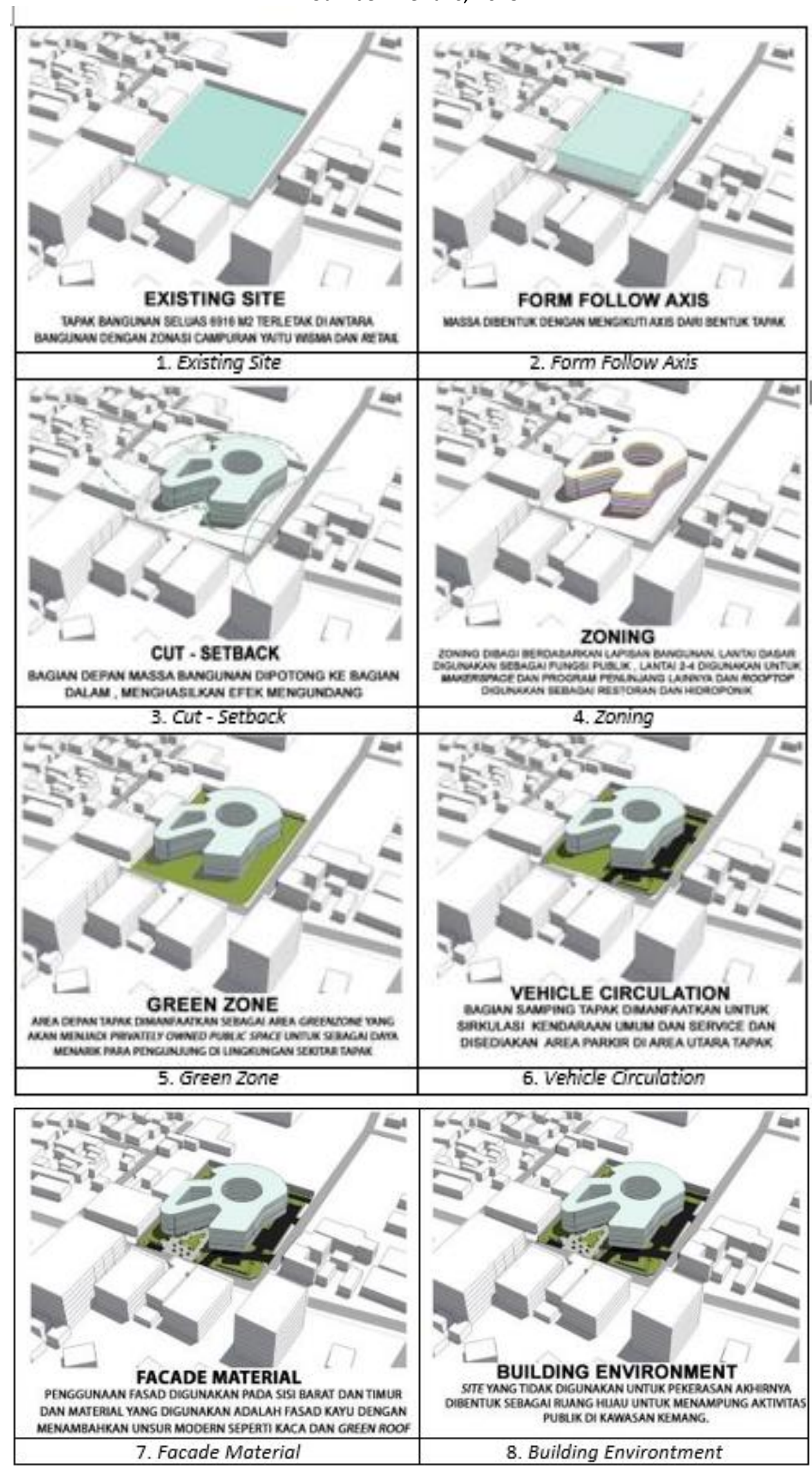


\section{Sasaran}

Pelaku kegiatan yang nantinya akan menggunakan Digital Art and Craft Makerspace dibagi menjadi dua kelompok, yaitu :

1. Wisatawan : wisatawan yang dimaksud merupakan wisatawan mancanegara dan wisatawan lokal. Kebutuhan dan aktivitas wisatawan berbeda dengan aktivitas penduduk lokal.

2. Penduduk lokal : Aktivitas, kegiatan, lokalitas, dan konteks penduduk lokal di jalan Kemang memiliki ciri khas tersendiri, sehingga dengan adanya proyek Digital Art and Craft Makerspace harus saling terhubung dan saling mendukung satu sama lain.

\section{Program}

Tabel 2. Program Arsitektur

Sumber: Penulis, 2019

\begin{tabular}{cccc}
\hline Project & Program & Sub-Program & Program Arsitektur \\
\hline \multirow{3}{*}{$\begin{array}{c}\text { Digital Art and } \\
\text { Craft Makerspace }\end{array}$} & Creation & Makerspace & Studio dan Bengkel \\
\cline { 2 - 4 } & Collaboration & Exhibition & Galeri \\
\cline { 2 - 4 } & \multirow{2}{*}{ Business } & Co-Working & Workspace \\
\cline { 2 - 4 } & & Support Services & Counsel Room \\
\cline { 2 - 3 } & & Retail & Counsel Room \\
\hline
\end{tabular}

Usulan program arsitektur yang pertama adalah Creation. Program yang termasuk dalam Creation adalah makerspace dan exhibition. Ruang-ruang ini bertujuan untuk mendorong keingintahuan, eksperimen dan kolaborasi. Hal ini dapat menginspirasi pemikiran baru dan saling bertukarpikiran untuk mendorong pertumbuhan ekonomi kreatif.
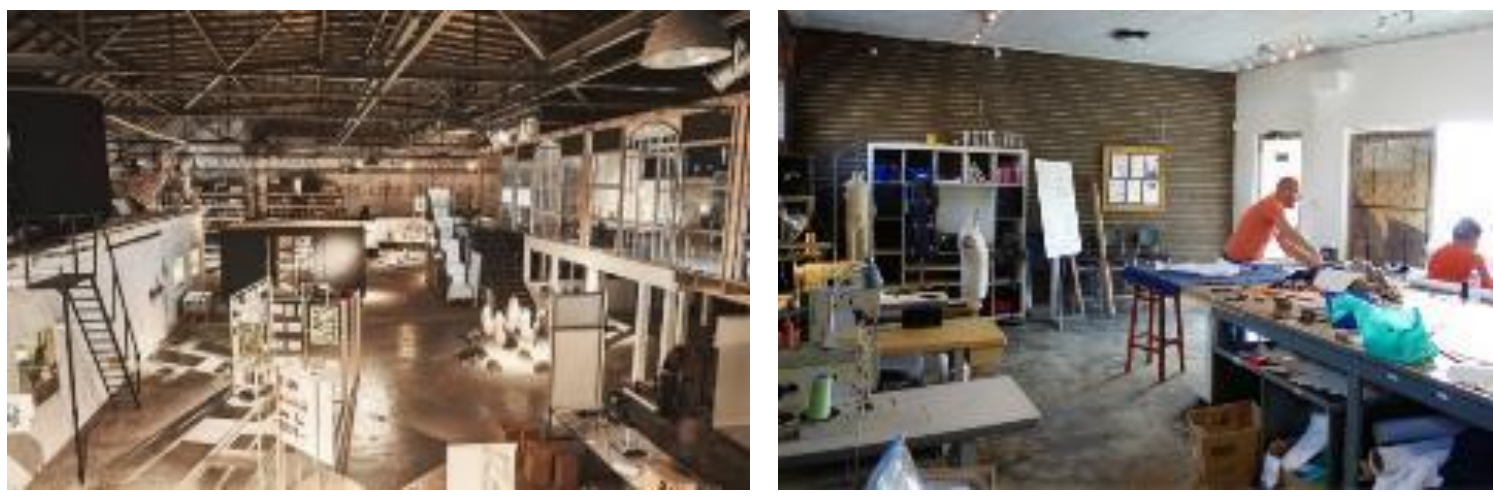

Gambar 7. Markerspace

Sumber : www.google.com, 2018

Program kedua adalah Collaboration. Program yang termasuk ke dalam Collaboration adalah workspace dan counsel room. Ruang kerja yang akan dibuat adalah sebuah ruang yang dapat memfasilitasi para generasi muda yang memiliki jiwa entrepreneur untuk memulai bisnis secara mendiri dengan melalui ekonomi kreatif. Ruang ini juga memiliki tujuan untuk mewadahi para generasi muda untuk bisa saling bertukar ide atau gagasan dalam memulai sebuah inovasi. 

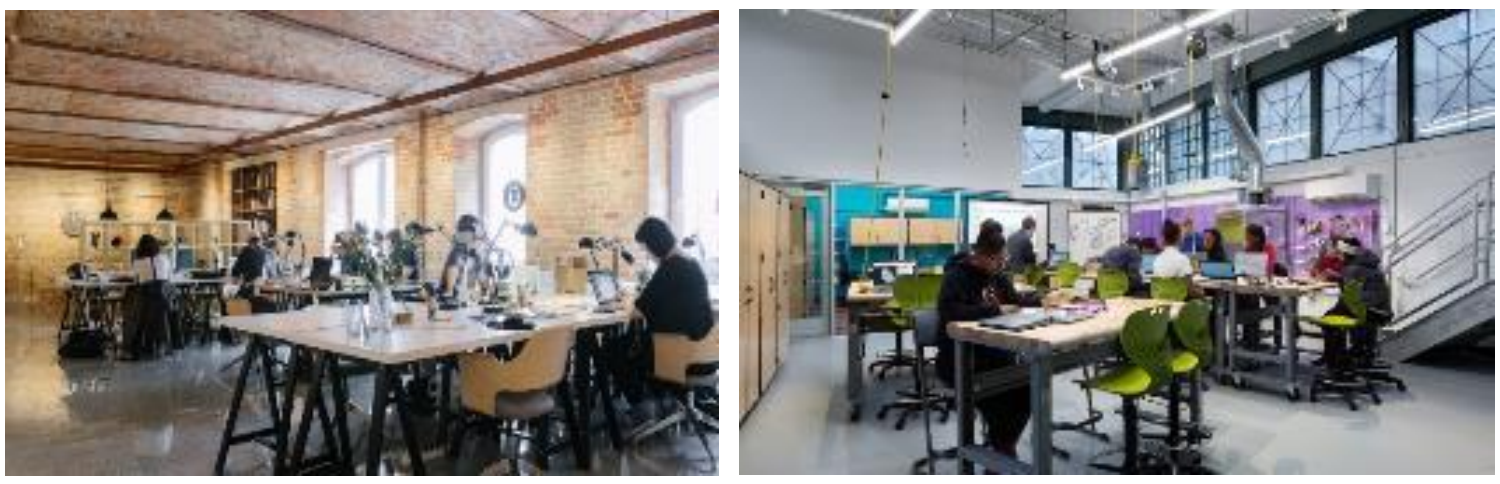

Gambar 8. Co-Working

Sumber : www.google.com, 2018

Program ketiga adalah Business. Program yang termasuk ke dalam business adalah support service dan retail. Ruang support service dimaksudkan untuk mengedukasi para generasigenerasi muda yang aktif untuk dapat diberikan konseling/ kelas mengenai teknik marketing dan promosi sebuah produk.
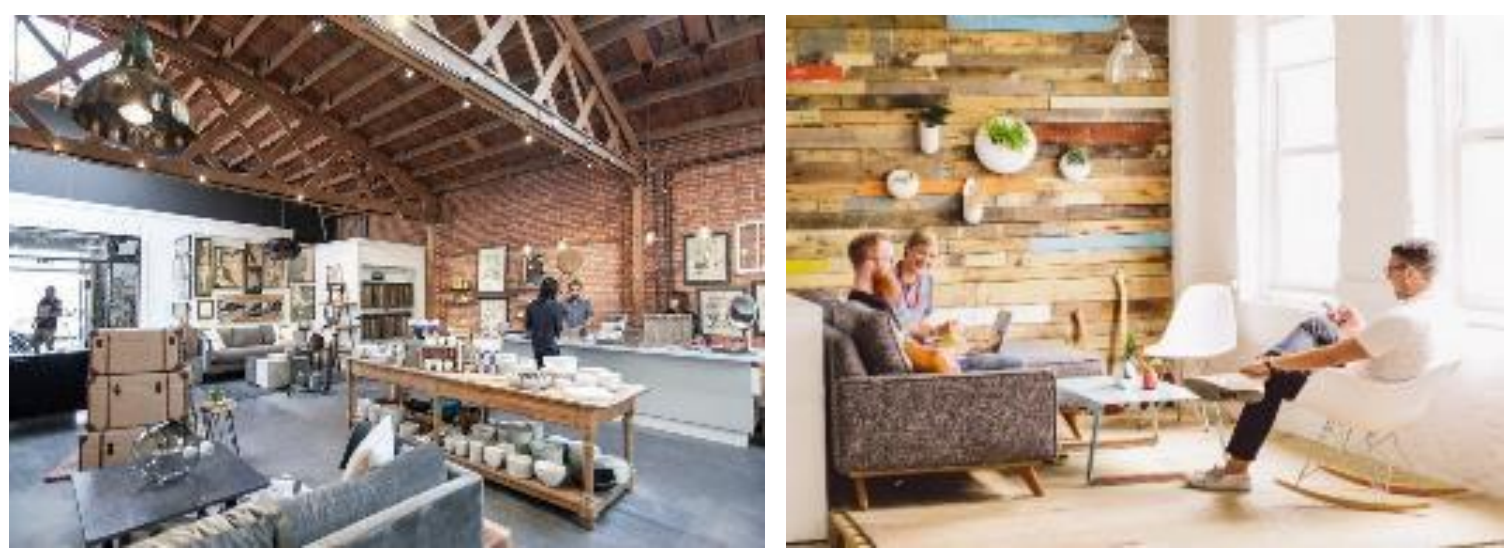

Gambar 9. Retail dan Counsel Room

Sumber : www.google.com, 2018

\section{Sistem Struktur Bangunan}

Struktur bangunan pada bagian kolom menggunaan kolom beton dengan diameter $50 \mathrm{~cm}$ dan $80 \mathrm{~cm}$. Besar kolom beton dihitung dengan menggunakan hitungan 1/12 bentang. Untuk bahan balok menggunakan bahan beton dengan ukuran 35/70 untuk ukuran balok induk dan ukuran 25/50 untuk ukuran balok anak. Plat lantai yang digunakan menggunakan bahan beton bertulang dengan ketebalan $20 \mathrm{~cm}$. Sedangkan pada bagian atap menggunakan rangka spaceframe serta penutup atap menggunakan glass panel \& etfe roof. 


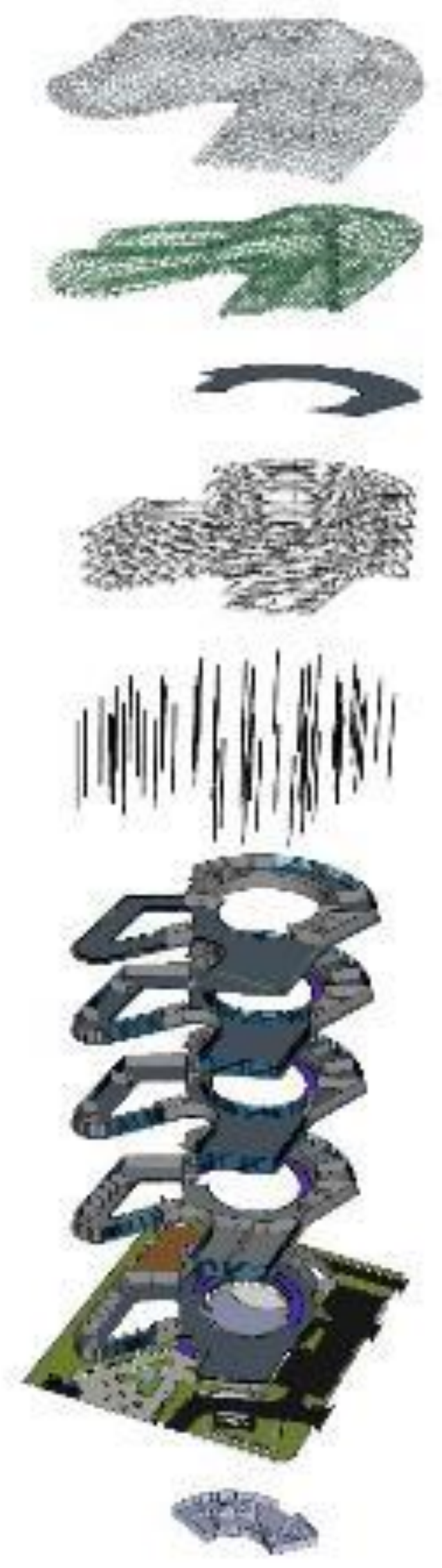

Gambar 10. Retail dan Counsel Room

Sumber: Penulis, 2019 


\section{KESIMPULAN DAN SARAN}

Industri kreatif di Indonesia dapat dipahami dalam konteks sosial dan budaya Indonesia, yang mana kreativitas dalam industri ini mencakup kreativitas yang berakar pada budaya lokal yang telah menjadi milik komunitas dan memanfaatkan ilmu pengetahuan serta teknologi dalam menciptakan produk dan layanan. Kreativitas dalam konteks industri kebudayaan ini biasanya tidak mengandalkan pemanfaatan teknologi baru tetapi lebih kepada kreasi akan desain produk yang berakar pada pengetahuan lokal.

Ketika merancang sebuah bangunan edukasi dan penelitian perlu dipahami lebih lanjut mengenai content atau isi yang akan diedukasikan, bagaimana cara mengedukasinya, metode edukasi apa yang dapat digunakan serta di mana titik vital yang dapat diangkat menjadi konsep utama bangunan. Salah satunya yaitu seperti kenaikan pertumbuhan industri kreatif yang menjalar dan tumbuh dari generasi-generasi millenial. Generasi yang akan mempunyai peran yang sangat besar terhadap pertumbuhan ekonomi kreatif. Faktor pertumbuhan tersebut dapat dikatakan sebagai sebuah proses di mana konsep perancangan mengkolaborasi proses ilmu pendidikan psikologi yang diterapkan pada sirkulasi serta studi setiap ruang bangunan yang memiliki konten penjelasan yang berbeda. Hal tersebut dapat menciptakan sebuah pengalaman ruang yang berbeda pada setiap ruang yang dilewati oleh pengunjung. Dari perbedaan tersebut menghasilkan kepribadian serta daya tangkap yang berbeda pada setiap ruang yang membuat setiap komponen ruang berhasil menceritakan sebuah pengalaman ruang yang berbeda-beda.

Mendirikan sebuah sarana edukasi tidak semata-mata membangun ulang sebuah bangunan yang kaitannya secara fisik, namun perpaduan dan pertimbangan pengunjung yang ada di dalamnya sangat penting untuk menjadi pedoman baru dalam mengedukasi pengunjung yang hadir misalnya dengan menerapkan suasana dan perasan ruang yang berbeda sesuai dengan edukasi yang disajikan di dalamnya serta hierarki ruang yang membawa sirkulasi perjalanan pengunjung dalam bangunan.

\section{REFERENSI}

Bekraf. (September 2017). Snapshot Promosi Produk Kreatif. www.bekraf.go.id . 12 Februari 2019.

Bekraf. (2017). Identities. www.bekraf.go.id . 14 Februari 2019.

Bekraf. ( September 2017). Snapshot Citra Merk Produk Kreatif. www.bekraf.go.id . 10 Februari 2019.

Bekraf. (Oktober 2017). Opus Ekonomi Kreatif. www.bekraf.go.id . 14 Februari 2019.

Heimsath, C. (1988). Behavioral Architecture, Toward an Accountable Design Process. New York : McGraw-Hill Book Co

Mangunwijaya, Y.B. (2013). Wastu Citra. Jakarta : PT Gramedia Pustaka Utama

Rullyana, Gema. (n.d). Arsitektur dan Perilaku Manusia. http://www.academia.edu/36159155/Arsitektur_dan_Perilaku_Manusia_Kajian_Arsitektur _pada_Bidang_Perpustakaan_.09 Februari 2019.

Rusmono, D. (n.d). Architecture \& Human Spatial Behaviour. https://www.academia.edu/36159113/Architecture_and_Human_Spatial_Behaviour.pdf_K ajian_Arsitektur_pada_bidang_perpustakaan_.10 Februari 2019.

Saputro, B. W. (2018). Penerapan Desain Arsitektur Perilaku pada Perancangan. Jurnal Arsitektur. 1(2) 